\title{
LETRAMENTO RACIAL E EDUCAÇÃO ANTIRRACISTA NAS AULAS DE LÍNGUA PORTUGUESA
}

\section{RACIAL LITERACY AND ANTI-RACIST EDUCATION IN PORTUGUESE LANGUAGE CLASSES}

\author{
Marivete Souta* \\ Ione da Silva Jovino***
}

Resumo: Objetivamos apresentar um recorte de uma pesquisa de Mestrado desenvolvida em 2016 em um colégio da rede estadual de educação da cidade de Ponta Grossa, Paraná, a fim de verificar se/quais conflitos de identidade racial aparecem nas produções de alunas(os) adolescentes negras(os) e brancas(os); os objetivos específicos consistiram em identificar o papel da escola e outras instituições e/ou meios na (re) construção da(s) identidade(s) raciais e analisar como uma sequência didática (SD), com o gênero relato autobiográfico pode contribuir para a construção da identidade étnico-racial, ao ser aplicada pela perspectiva teórica do letramento racial crítico e da educação antirracista. Embasaram este estudo Besset e Castro (2008) e Ferreira (2006; 2014; 2015). Apresentaremos a sequência didática, na qual fazemos reflexões sobre as relações étnico-raciais a partir da intervenção e o impacto que causou na ressignificação da branquitude.

Palavras-chave: Identidade; Letramento Racial Crítico; Língua Portuguesa.

ABSTRACT: We aim to present a cutout of a Master research developed in 2016 in a public state school in the city of Ponta Grossa, Paraná. The purpose of this research was to point out which are the conflicts of racial identity that appear in the compositions of teenager black students and white ones. The specific goals of this study were to identify which role the school and other institutions and/ or means play in the (re) construction of racial identity and analyze how a Didactic Sequence (DS) with the autobiographical genre can help in the construction of ethical racial identity. It was applied in the perspective of the theory of racial critical literacy and anti-racial education. In order to do so, the study was based on Besset and Castro (2008) and Ferreira (2006, 2014,

\footnotetext{
"Mestre em Estudos da Linguagem - UEPG. Professora da rede estadual do Paraná. E-mail: marivete.souta@gmail. com.

"Doutora em Educação pela Universidade Federal de São Carlos, Professora do Departamento de Estudos da Linguagem e do Mestrado em Estudos da Linguagem da Universidade Estadual de Ponta Grossa- UEPG. E-mail: ionejovino@gmail.com.
} 
2015). We will present the Didactic Sequence and how the reflections on ethnic-racial relations from the intervention had an impact on the demeaning of whitening.

KeYwords: Identity; Critical Racial literacy; Portuguese Language.

\section{INTRODUÇÃO}

A partir de uma pesquisa de mestrado realizada em 2016, este artigo aspira a refletir sobre a metodologia utilizada no estudo que será retratado. O propósito deste trabalho consistia em verificar se/quais conflitos de identidade racial aparecem nas produções de alunas(os) negras(os) e brancas(os); os objetivos específicos resumem-se em: identificar o papel da escola e outras instituições e/ou meios na (re)construção da(s) identidade(s) raciais e analisar como uma SD, com o gênero relato autobiográfico pode contribuir para a construção da identidade étnico-racial ao ser aplicada pela perspectiva teórica do letramento racial crítico e da educação antirracista. O presente estudo foi desenvolvido em uma escola da rede estadual de educação da cidade de Ponta Grossa, no estado do Paraná.

O problema que gerou o objeto de estudo desta pesquisa surgiu em 2014, no mesmo colégio onde este trabalho foi desenvolvido, durante a promoção de uma atividade referente ao Dia da Consciência Negra. Algumas/alguns alunas(os) negaram-se a participar de uma sessão de fotos sob a alegação de que não eram negras(os). Essa reação que partiu deles instigou uma reflexão sobre a questão racial em uma das autoras deste artigo. Assim, optou-se por desenvolver a pesquisa no colégio mencionado, primeiramente, por ser o lócus de surgimento do problema da pesquisa que será retratada e também, porque uma das autoras ministra aulas nessa escola.

Inicialmente, a pesquisa contou com a participação de 63 estudantes dos $9^{\circ}$ anos do período matutino. A aplicação da intervenção durou 13 aulas, sendo que 6 aulas foram realizadas no laboratório de informática.

Durante o processo de geração de dados ocorreram alguns imprevistos, como desistência, transferência e remanejamento de alunos; isso fez com que o grupo que fez parte do trabalho diminuísse para 57 estudantes, e desses 57 alunos, 53 redigiram o relato escrito.

Primeiramente, neste artigo apresentaremos a perspectiva da intervenção: o letramento racial crítico e educação antirracista; em seguida, apresentaremos a sequência didática desenvolvida; na seção seguinte, "repensando as relações étnico-raciais a partir da intervenção", analisaremos o impacto da intervenção na ressignificação da branquitude, e na última seção temática apresentamos as considerações finais do trabalho. 


\section{A INTERVENÇÃO NA PERSPECTIVA DO LETRAMENTO RACIAL CRÍTICO E EDUCAÇÃO ANTIRRACISTA}

Optamos pela pesquisa-intervenção, pois conforme Besset e Castro (2008, p. 11) salientam, é por intermédio dela que se "descortina um modo de fazer pesquisa fecundo na articulação entre o que se investiga e como se investiga”, assim, é fazer uma pesquisa com adolescentes e jovens, e não sobre eles.

Uma das principais agências de letramentos no mundo contemporâneo é a escola, Rojo (2009, p. 52) observa que se deve "estabelecer a relação, a permeabilidade entre as culturas e letramentos locais/globais dos alunos e a cultura valorizada que nela circula ou pode vir a circular". Essa intervenção, na perspectiva do letramento racial crítico e da educação antirracista, permite o aprendizado e a problematização do discurso hegemônico da globalização e os significados antiéticos que não têm respeito à diferença, pois a escola deve, de maneira crítica, abordar textos e produtos das diversas culturas e mídias para que se desvelem suas intenções, finalidades e ideologias.

O letramento crítico, para Ferreira (2015), é como uma ferramenta para entender o contexto político, ideológico e social em que o aluno se insere. Segundo Ferreira (2014, p. 250), "vale dizer que, para termos uma sociedade mais justa e igualitária, temos que mobilizar todas as identidades de raça branca e negra para refletir sobre raça e racismo e fazer um trabalho crítico no contexto escolar [...]". O conjunto de instrumentos pedagógicos de que o professor vai lançar mão para trabalhar nessa perspectiva é o letramento racial crítico.

Optamos pela Teoria Racial Crítica neste trabalho, pois, segundo Ferreira (2015, p. 131), para essa teoria "a narrativa é importante, pois uma das premissas da Teoria Racial Crítica é a utilização de narrativas, de autobiografias, de contar histórias não hegemônicas (counterstories)". Neste trabalho utilizamos como um dos instrumentos de pesquisa os relatos pessoais, isto é, o relato autobiográfico.

Ferreira (2006, p. 33) afirma que o ensino crítico "relaciona-se com a forma como se ensina em sala de aula, seus objetivos, seu papel na sociedade e a habilidade de agir reflexivamente". A teoria Racial crítica, conforme Ferreira (2014) destaca o enfoqueà branquitude e como trabalharemos com as questões raciais enfocando tanto a raça branca quanto a raça negra. Encontramos na Teoria Racial Crítica um excelente suporte teórico para este trabalho. Ferreira (2014) esclarece que pela Teoria Racial Crítica o que é construído em nome do poder pode ser discutido e desconstruído em nome da igualdade e da justiça social.

Piza (2005) afirma que a branquitude é a fase em que se superou a branquidade e foi esse caminho que tentamos percorrer na aplicação desta pesquisa, ou seja, trazer para as/os estudantes o papel do branco na estruturação do racismo, para que por meio do letramento racial crítico, os alunos pudessem passar para a fase de superação da branquidade em direção a uma branquitude crítica, assim como destacaremos no desenvolvimento deste artigo. 


\section{A SEQUÊNCIA DIDÁTICA DESENVOLVIDA DURANTE A INTERVENÇÃO}

A SD que foi executada durante o projeto de pesquisa tem como suporte teórico Marcuschi (2008), Dolz e Schneuwly (2004) e Ferreira (2006). Realizamos adaptações conforme o contexto de sala de aula, a temática, o tempo e as características das(os) alunas(os). Os trabalhos realizados por Orlando (2013) e Souza, Corti e Mendonça (2012) também influenciaram no planejamento dessa SD, a qual descreveremos a seguir.

Primeiramente, apresentamos o motivo que nos estimulou a fazer esta investigação, o objetivo desta pesquisa, a sua importância, a importância da participação das(os) alunas(os) e a metodologia que utilizamos para realizar esta pesquisa.

A SD foi dividida em módulos. No primeiro módulo foi apresentada a situação de comunicação e a atividade Linha do Tempo, que é um resgate dos fatos marcantes na vida das(os) alunas(os). Posteriormente, cada aluna(o) apresentou a linha do tempo da(o) colega para exercitar a troca de papéis; a seguir, foi realizada uma reflexão sobre como elas/eles se sentiram ao estar no lugar do outro. Esse exercício, conforme Souza, Corti e Mendonça (2012), favorece o acionamento da memória. O próximo passo foi detalhar a linha do tempo com o enriquecimento que elas/eles tiveram no momento da interação.

No $2^{\circ}$ módulo foi apresentado o primeiro relato autobiográfico intitulado Assim pude me trazer de volta pra mim de Pablo Ferreira Biglia, para o reconhecimento do gênero textual. No $3^{\circ}$ módulo foi promovida uma pesquisa em dicionários e numa tabela sobre o gênero relato autobiográfico, e foram aplicados alguns exercícios retomando a pesquisa, utilizando os exemplares do livro Experiências Projeto Equidade na Pós-Graduação: perspectivas, debates e histórias de vida.

As(os) alunas(os) realizaram a leitura de um relato autobiográfico escolhido por elas/ eles, buscando detectar características do relato na tabela. Nesse momento, houve um intervalo na aplicação da SD, porque houve os Jogos Interclasse na escola, o JISO. Na semana seguinte, o colégio foi ocupado pelo Movimento Estudantili1, por essa razão o próximo módulo foi adiado para o retorno das aulas.

No $4^{\circ}$ módulo, antes de irmos ao laboratório de informática para assim acessarmos dois relatos autobiográficos e um vídeo, os alunos receberam as orientações sobre como a atividade deveria ser desempenhada e as perguntas que deveriam ser respondidas.

Esse foi um momento de reflexão sobre a questão racial, que foi observada de forma diferente, ou seja, o olhar para o espelho, para os privilégios de ser branca(o). Para tanto, foram

\footnotetext{
1"No mês de outubro de 2016, professores e servidores públicos de toda a região do estado do Paraná promoveram uma greve que durou 1 mês, por estarem insatisfeitos com o fato de o então governador da região, Beto Richa, ter decidido não cumprir com o compromisso de pagamento do salário de data-base para a categoria. Com isso, muitas escolas da rede pública de ensino e algumas universidades foram ocupadas por estudantes insatisfeitos com a educação no país, pois, naquela época, o governo federal recentemente havia aprovado alterações na matriz curricular do Ensino Médio e a Proposta de Emenda Constitucional (PEC) 241 (que cria teto para gastos públicos)”. (SOUTA, 2017, p. 79)
} 
preparadas perguntas extras, um plano " $\mathrm{B}$ " para o caso de as respostas das(os) alunas(os) não atingirem o objetivo da atividade anterior; assim, o exercício poderia direcionar a atenção para as questões raciais. Em uma das turmas o plano B foi acionado, pois houve dificuldade para o direcionamento que se almejava. Voltando à sala de aula, foi aplicado o exercício $A$ caminhada dos privilégios ${ }^{2}$, que é uma adaptação de um exercício, que segundo o site oficial do Instituto da Mulher Negra GELENDÉS, é bastante utilizado em dinâmicas de grupo nos EUA, para que se visualize os privilégios de cada pessoa. Esse exercício também possibilita um olhar para si mesmo.

No $5^{\circ}$ módulo, trabalhamos com o texto Assim pude me trazer de volta para mim, que também é um exemplo de relato autobiográfico, o qual utilizamos para exercitar a análise linguística com os alunos. No $6^{\circ}$ módulo foi realizada a primeira produção de narrativa autobiográfica, a partir de algumas questões dadas com o tema "Como me dei conta de que sou branca(o), negra(o)".

No $7^{\circ}$ módulo as(os) alunas(os) estavam com uma ficha em mãos, com elementos que deveriam ter sido priorizados nos relatos autobiográficos. Cada aluna(o) releu o seu texto, que foi recolhido após a primeira escrita, e o reescreveu.

O texto foi recolhido novamente, e dessa vez ele foi revisado pela professora/pesquisadora, pois, de acordo com a metodologia da SD, os textos devem ser revisados para apontamentos de correções que deverão ser feitas, para verificar se houve compreensão do gênero e se houve inadequações gramaticais. A partir disso revisamos os pontos que não foram bem assimilados pelos grupos, para depois realizarmos a refacção. No $8^{\circ}$ módulo as(os) alunas(os) fizeram a editoração do texto.

\section{REPENSANDO AS RELAÇÕES ÉTNICO-RACIAIS A PARTIR DAINTERVENÇÃO}

Agora partiremos para a parte de análise final da intervenção pedagógica na perspectiva do letramento racial crítico. Para tanto, antes de tudo, fora realizada uma leitura de todos os relatos autobiográficos a fim de tecer um perfil dos sujeitos da pesquisa, lançamos mão de excertos de narrativas e das anotações do diário de bordo para responder às perguntas de pesquisa; agrupamos os fragmentos de narrativas e anotações do diário de bordo por categorias, de acordo com as questões (foram elencadas as fontes/instrumentos para análise de cada categoria subjacente a cada pergunta de pesquisa).

É pertinente salientar que foi necessário voltar às narrativas e buscar os sujeitos que se autoidentificaram dentro das categorias: branca(o), negra(o), parda(o), morena(o) conforme a heteroclassificação brancas(os) e negras(os). Para facilitar a releitura e a reconsulta de dados,

\footnotetext{
${ }^{2}$ As adaptações são referentes à modificação de algumas perguntas que foram adaptadas conforme a temática da SD e a própria aplicabilidade da atividade no que corresponde ao espaço de seu desempenho, devido à infraestrutura do colégio.
} 
elaboramos um quadro com nomes e pseudônimos ${ }^{3}$, com isso conseguimos visualizar o sujeito e tentamos lembrar atitudes e comportamentos que pudessem colaborar para a análise. Esse processo exigiu cruzamento de dados para interpretá-los.

Analisamos os relatos autobiográficos trazendoalguns excertos que ilustram a ressignificação da branquitude por parte dos sujeitos desta pesquisa. Alguns relatos trazem mais de uma frase reafirmando a ressignificação da branquitude, entretanto optamos por colocar uma frase de cada relato. Dos 28 relatos de sujeitos brancos, 10 (3\%), trouxeram frases que demonstraram ressignificação da branquitude.

Embora não tenhamos atingido todos os educandos, percebemos, ao analisar o diário de bordo, que a intervenção teve um papel importante para a mudança na maneira como os sujeitos passaram a pensar as relações raciais. Apresentaremos primeiramente a análise dos excertos dos relatos e na sequência efetivaremos um cruzamento desses relatos com os dados do diário de bordo, como é possível observar na tabela a seguir:

TABELA 1 - Número de estudantes brancas(os) que se surpreenderam ou não ao descobrir que possuem maiores privilégios do que os negros

\begin{tabular}{c|c|c}
\hline \multirow{2}{*}{} & \multicolumn{2}{|c}{$9^{\circ} \mathrm{a}$} \\
\cline { 2 - 3 } & \multicolumn{2}{|c}{ Brancas(os) } \\
\cline { 2 - 3 } Total & Surpreenderam-se & Não se surpreenderam \\
\cline { 2 - 3 } & 16 & 13 \\
\cline { 2 - 3 } & \multicolumn{2}{|c}{ Fonte: Souta (2017, p. 111) } \\
\hline
\end{tabular}

Durante a atividade Caminhada dos Privilégios, $55 \%$ das/dos brancas(os) revelaram ter se surpreendido ao descobrir que possuíam mais privilégios do que as/os negras(os); no final dessaintervençãotodas(os) as(os) pesquisadas(os) brancas(os) revelaram ter consciência de que têm vantagens por serem brancas(os). A(o) branca(o) declara ser "normal" ser branco(a), no sentido de pertencer ao modelo universal de ser humano, são privilegiados de alguma forma. Não tinham parado para pensar no que éser branco; no entanto, sempre perceberam que o negro é discriminado.

Bento (2014, p. 46), ao falar de "pactos narcísicos", diz que são alianças, contratos e pactos inconscientes "por meio dos quais os sujeitos se ligam uns aos outros e ao conjunto grupal, por motivos e interesses superdeterminados". Quando os sujeitos brancos desta pesquisa afirmam que ser branco é ser "normal", possivelmente estão querendo expressar o pertencimento ao grupo considerado modelo universal de ser humano.

${ }^{3}$ Foi sugerido aos alunos que eles poderiam escolher nomes de ídolos e personalidades famosas para serem seus pseudônimos. 
Bento (2014) completa essa linha de raciocínio, dizendo que grita na subjetividade contemporânea dos brasileiros, em particular dos brancos, beneficiários simbólicos ou concretos dessa realidade, essa herança silenciada. Esse pacto inclui o medo e o silêncio, porque a escravidão envolveu violação institucionalizada de direitos, apropriação indébita simbólica e concreta. No início da intervenção, de 49 brancos, 16 revelaram não ter noção dos privilégios que tinham por serem brancos, no entanto, no final da intervenção, todos relataram terem noção dos privilégios.

Moreira (2014), se referindo ao pacto narcísico, diz que o que conduz os brancos ao medo do outro é o medo que o branco sente de perder os privilégios. A tendência do branco ao isolamento em locais de brancos tem o intuito de fortalecer os laços da branquitude, deixando o não-branco à margem, e isso pode ser inconsciente. Laborne (2014) afirma que fazer um questionamento sobre um poder simbólico, que está baseado em valores "transparentes" e "neutros", na crença de uma supremacia branca, parece essencial para a compreensão das relações raciais no Brasil.

Para elas/eles ser branca(o) é ser "normal". Bento (2014, p. 30) explica que a distorção do lugar do branco na situação das desigualdades raciais no Brasil, o silêncio e a omissão "têm um forte componente narcísico, de autopreservação, porque vem acompanhado de um pesado investimento na colocação desse grupo como grupo de referência da condição humana". Assim, acreditamos que a afirmação repetida no relato: "ser branca(o) é se sentir normal", provavelmente vem dessa ideia de modelo universal de ser humano. Agora analisaremos alguns trechos dos relatos autobiográficos produzidos pelos alunos:

O branco sofre um preconceito e o negro sofre outro, que é bem pior, pois ele pode ser preso sem fazer nada, já o branco não [...] (Julianny, branca, relato autobiográfico, 18/10/2016).

Pensei comigo mesmo, EU NUNCA havia pensado nisso, ENTÃO EU VI que a cor de pele influencia no pensamento das pessoas [...] (Light Iagami, branco, relato autobiográfico, grifos meus, 18/10/2016) (SOUTA, 2017, p. 164).

Tanto Julianny quanto Light Iagami demostraram que a intervenção impactou tanto na forma como eles se viam e como viam o outro. Julianny, ao analisar o tipo de preconceito que o negro sofre, percebe que isso pode acarretar numa situação de injustiça. O que ela compreende é que é mais comum o negro ser injustiçado, algo que nos remete ao privilégio apontado por Cardoso (2014) como característica principal da branquitude.

Julianny parece compreender que por ser branca, a pessoa pode ser considerada de antemão e sempre uma pessoa boa, estando livre de suspeita pela polícia, baseada na cor da pele, corre menores riscos de até ser presa injustamente. O aluno Light Iagami, ao revelar que nunca tinha pensado sobre a sua própria cor e dizer que percebeu que a cor da pele influencia 
no pensamento das pessoas, parece compreender que os brancos desempenham papel crucial nas relações raciais. Ele faz algumas reflexões importantes depois de relatar um episódio de racismo:

[...] será que é por eu ser branco? Pensei comigo mesmo (Light Iagami, relato autobiográfico, 18/10/2016). Demostrando pensar também sobre os privilégios que tem: eu sendo branco, isso me dá privilégios que às vezes os negros não têm (Light Iagami, relato autobiográfico, 18/10/2016). (SOUTA,2017, p. 165).

Verificando o diário de bordo, percebemos que as reflexões não avançaram a partir dessa percepção, pelo menos o aluno Light Iagami não expressou mais avanços durante o desenvolvimento da intervenção. Ele percebeu que tinha privilégios por ser branco, que isso pode influenciar no pensamento das pessoas, mas não demonstrou ter se posicionado contra a branquitude. Cremos que o trabalho na perspectiva do letramento racial crítico e da educação antirracista deve ser contínuo, porque o tempo para cada um avançar é diferente, alguns avançaram mais rapidamente, como no caso que discutiremos na sequência depois de fazermos uma explicação sobre a perspectiva desta intervenção.

Antes de prosseguir, relembraremos como entendemos o trabalho na perspectiva do letramento racial crítico e da educação antirracista, pois foi isso que a aplicação da intervenção se propôs a fazer. De acordo com Ferreira (2014), para se fazer um trabalho nessa perspectiva, é preciso saber que o que é construído em nome do poder pode ser desconstruído em nome da justiça social e da igualdade, pois o ensino crítico está relacionado à forma de ensinar em sala de aula, seus objetivos, o papel que é desempenhado na sociedade e a reflexão sobre o modo de agir.

Os professores, ao adotarem um objetivo crítico em suas aulas, colaboram no sentido de desenvolverem uma consciência própria como agentes sociais. É preciso que alunos e professores reflitam sobre suas experiências de vida, que entendam a relação social entre raça, etnia e escola. Quando desafiamos os estereótipos, somos empoderados, transformando a cultura da escola. O letramento racial crítico pode ser uma possibilidade para a aplicação da Lei 10.639/03.

Dentro e fora da escola, o letramento racial crítico pode dar voz aos indivíduos tanto negros quanto brancos, nesse sentido, isso pode contribuir para diminuir a exclusão, (FERREIRA, 2006). Na sequência, verificamos o que os relatos autobiográficos revelaram sobre a ressignificação da braquitude. Vinte e oito sujeitos se declararam brancos nos relatos autobiográficos, desses, 10 relatos trazem frases que revelam ressignificação da branquitude, conforme ilustra a tabela a seguir. 
TABELA 2 - Frases descritas pelas(os) alunas(os) de ressignificação da branquitude

\begin{tabular}{l|c}
\hline Brancas(os) & Ocorrências \\
\hline Frases dos relatos que revelam ressignificação da branquitude & 1 \\
\hline Temos mais privilégios, mas nos sentimos assim só por causa do preconceito & 1 \\
\hline Ser branco significa ser privilegiado, [...] privilegiados deveriam ser todos. & 2 \\
\hline Minha cor, branca pode influenciar na concretização dos meus sonhos, infelizmente. & 1 \\
\hline $\begin{array}{l}\text { Acho que minha cor poderá influenciar um dia meu contratante, mas não tenho } \\
\text { como mudar isso. }\end{array}$ & 1 \\
\hline $\begin{array}{l}\text { Ser branca é a pessoa que irá ter mais privilégios que uma pessoa negra e isso irá } \\
\text { fazer você pensar sobre isso. }\end{array}$ & 1 \\
\hline $\begin{array}{l}\text { Por eu ser branco eu posso ter vantagem de uma forma injusta. } \\
\text { [...] Será que é por ser branco? Pensei comigo, eu nunca havia pensado nisso, então } \\
\text { eu vi que a cor da pele influencia no pensamento das pessoas }\end{array}$ & 1 \\
\hline \begin{tabular}{l} 
Total \\
\hline
\end{tabular}
\end{tabular}

Fonte: Souta (2017, p. 166).

Entendemos branquitude no sentido abordado por Piza (2005; 2014). Primeiramente é preciso que os brancos tenham noção dos privilégios, para depois tomar uma posição contra eles. Partindo desse pressuposto, durante a pesquisa, quando discutimos sobre essa questão, encontramos em uma das autobiografias a seguinte afirmação: "Ser branca é a pessoa que popularmente irá ter MAIS PRIVILÉGIOS que uma negra e ISSO IRÁ FAZER VOCÊ PENSAR SOBRE ISSO" (Selena Gomes, branca, relato autobiográfico, 18/10/2016, grifos meus) (SOUTA, 2017, p. 166).

Selena reflete ao se dar conta de que é portadora de privilégios por ser branca e ainda mais, posiciona-se ao dizer: "e isso vai fazer você pensar sobre isso", ou seja, saber que uma pessoa, por ser negra, terá menos chances na vida, muda a forma de pensar seu papel nessa relação racial. Nogueira (2014), ao falar de identidade, diz que ela pode ser compreendida como a história de nossas metamorfoses em busca da emancipação que nos humaniza.

Porém, a emancipação que dá sentido ético pode ser prejudicada ou impedida pela violência e relações de coerção e opressão, tornando a metamorfose desumanização. O efeito pode ser a produção de uma identidade obstada ao invés de produzir uma identidade afirmativa. Nogueira (2014) afirma que é assim que se revela a natureza intrinsecamente política da identidade. Por isso a autora afirma ser fundamental a promoção de pesquisas que abordem essa temática, para sabermos como nos tornamos quem nós somos. Agora analisaremos o próximo trecho dos relatos autobiográficos produzidos pelos alunos:

Sentir-se branca é algo bom, dá um ar de superioridade, de que temos mais privilégios, mas nos sentimos assim só por causa do preconceito. 
SENTIR-SE BRANCO OU NEGRO DEVIA SER O MESMO SENTIMENTO (Anny, branca, relato autobiográfico, 18/10/2016, grifos meus). (SOUTA, 2017, p. 166).

A reflexão também faz Anny perceber o papel do branco nas relações raciais quando ela afirma: "Sentir-se branca é algo bom, dá um ar de superioridade, de que temos mais privilégios". O ar de superioridade que sente advém dos privilégios, e isso só é possível por causa do preconceito. O reconhecimento dos privilégios, conforme Jesus (2014) menciona, é o primeiro passo para ações de combate a eles por parte do branco, por meio da conscientização.

A aluna Anny também demonstra ter compreendido que só tem privilégios por causa do preconceito quando usa a conjunção adversativa "mas", dando ideia de oposição, contrariedade, indicando a sua percepção sobre as desigualdades raciais em: "mas nos sentimos assim só por causa do preconceito".

Depois de refletir, a aluna conclui: "sentir-se branco ou negro devia ser o mesmo sentimento". Acreditamos que esse exercício trabalhado na sala de aula possa ser um caminho para que esses indivíduos, que possuem um letramento racial crítico, possam transformar essa conscientização em práticas que venham de encontro à branquitude.

O relato de Gran Bell também traz esse reconhecimento. Consideramos importante explicar que ele relata nunca ter pensado na cor de sua pele antes da intervenção. Relembramos aos leitores que voltamos às anotações do diário de bordo, para entender se realmente houve ressignificação da branquitude. Ao dizer: "acho que a minha cor poderá influenciar um dia sim. Mas não tenho como mudar o pensamento do meu contratante" (Gran Bell, relato autobiográfico, 18/10/2016). (SOUTA, 2017, p. 167). O aluno demonstra reconhecer que uns são mais iguais do que outros. Moreira (2014) afirma que ressignificar a branquitude é a tomada dessa consciência.

Ao dizer: "mas não tenho como mudar o pensamento do meu contratante", remete ao que afirma Piza (2005), que a branquitude não diz respeito aos discursos ingênuos dos que dizem que somos todos iguais, mas ao contrário, reconhece que uns são mais iguais do que outros.

Espera-se que essas/esses alunas(os) possam, no futuro, ao exercerem seus papéis de "contratantes", a partir do letramento racial crítico, agir de forma diferente a essa maneira preconceituosa à qual Gran Bell se refere. Como contratado, ele talvez não possa fazer mudanças, mas como contratante poderá romper com esse processo.

Ferreira (2014) enfatiza que as relações de poder estão em toda parte, assim, o poder pode ser exercido por todas as pessoas; não obstante, algumas pessoas ou grupos exercem maior influência do que outros, algo que dependerá do local de onde falam, de sua raça, sexualidade, gênero e classe social. Nós como professoras possuímos o intuito de educar cidadãos 
críticos sobre as relações raciais, que possam promover mudanças na sociedade para que tenhamos menos desigualdades.

A mudança de atitude, a ação, é o que se espera de alguém como Santana que, como Gran Bell, sente-se ainda impotente diante das injustiças que observa na sociedade. Confira isso no excerto a seguir: "Já presenciei vários casos de racismo, mas não me lembro muito bem de como aconteceu. Quando eu vejo algo parecido FICO OBSERVANDO QUIETA, MAS FICO IMPRESSIONADA COM CERTAS ATITUDES” (Santana, branca, relato autobiográfico, 18/10/2016, grifos meus). (SOUTA, 2017, p. 168).

Assim:

Ser um/a branco/a antirracista incide sobre a criticidade dos sujeitos em relação a sua posição racialmente privilegiada e a propensão à desconstrução, a destruição objetiva deste lugar. Não há um passe de mágica em que de um dia para o outro acordamos desenraizada/os, livres de tudo aquilo que nos constrói socialmente e psicologicamente como sujeitos diferenciados, bem como o processo não ocorre somente de dentro para fora, mas também em uma dinâmica inversa e talvez está nisto o nosso maior desafio: desconstruir o racismo no "sistema-mundo". [...] $\mathrm{O}$ antirracismo não deve ser compreendido estritamente como um estado, mas uma agenda de luta. (LOPES, 2016, p. 231-232).

O objetivo de um trabalho na perspectiva do letramento racial crítico e da educação antirracista é de que o mesmo não se silencie, mas, pelo contrário, discuta e se aprofunde no assunto. Espera-se que, por meio da continuidade do trabalho nessa perspectiva as(os) alunas(os) modifiquem a maneira de agir.

Em sua pesquisa, Laborne (2014, p. 136) verifica que alguns depoimentos apresentaram "a possibilidade de uma construção identitária do sujeito branco que, apesar de usufruir desse lugar de poder, questiona os privilégios simbólicos e materiais associados a seu grupo, ressignificando sua própria identidade racial."

Diante de uma branquitude que questiona a própria hegemonia branca, o primeiro passo para uma ressignificação da branquitude é reconhecer que os privilégios existem. Retomando Piza (2005, p. 06), ao contrário dos que afirmam que somos todos iguais perante a lei, ou perante Deus, ter uma atitude antirracista é reconhecer que alguns são mais iguais que outros, revertendo "o processo de se situar no espaço dos mais iguais para reivindicar a igualdade plena e de fato, para todos". Pesquisadoras como Cavalleiro (2012) e Jesus (2014) trazem dados sobre o papel do branco nas relações raciais e a força da branquitude atuando no ambiente escolar, acentuando a necessidade de que essa seja ressignificada. Cavalleiro (2012, p. 72) destaca: 
A familiaridade com a dinâmica da escola permite perceber a existência de um tratamento diferenciado e mais afeto dirigido às crianças brancas. Isso é bastante perceptível quando analisado o comportamento não verbal que ocorre nas interações professor/aluno branco. Nelas é natural o contato físico, acompanhado de beijos, de abraços e de toques. Isso é bastante visível no horário da saída, quando os pais começam a chegar para pegar seus filhos. A menina Solange (branca) despede-se da professora com um beijo e esta retribui. Observando o término de um dia de aula, foi possível contabilizar um número três vezes maior de crianças brancas sendo beijadas pelas professoras em comparação às crianças negras: dez crianças brancas para três negras.

Jesus (2014) também percebe em sua pesquisa que as imagens direcionadas aos estudantes do nível fundamental são completamente diferentes do visual dos estudantes que frequentam o colégio, que têm fenótipos negros quanto à cor de pele, espessura dos lábios, textura de cabelo. As crianças que estão nas imagens nas paredes da escola na qual a autora fez a pesquisa não condizem com as crianças negras que lá estudam.

Esses estudos mostram que, primeiramente, é preciso que nós, educadores, tenhamos o letramento racial crítico para poder ressignificar a nossa branquitude, num exercício que se opõe à branquidade, para poder trabalhar em prol de uma educação que vise uma sociedade mais justa. Devemos tomar cuidado não só com as imagens que circulam na escola, mas analisar também as imagens presentes nos livros didáticos, que ainda reforçam muitos estereótipos. (FERREIRA, 2014).

No final da intervenção, depois de refletirmos sobre o papel do branco nas relações raciais, todos, brancas(os) e negras(os), perceberam que o privilégio existe, o que trouxe uma grande mudança de visão sobre as relações raciais, proporcionada pelas leituras e reflexões a partir das atividades da intervenção. Cremos que a percepção dos privilégios foi fundamental para contemplarmos esses resultados.

Desse ponto em diante, intercalamos anotações do diário de bordo, para mostrar como durante a intervenção ocorreu a ressignificação da branquitude. Reiteramos que as filmagens e/ou gravações foram fundamentais para a complementação dos dados do diário de bordo, pois com mais de trinta alunas(os) em cada uma das duas turmas que pesquisamos, muitas vezes ocorreram fatos importantes durante as discussões que foram complementados com dados filmados e/ou gravados, pois é difícil parar a aula para fazer as anotações.

Uma pesquisa que se vale da aplicação de uma intervenção na sala de aula pode perder muitos dados importantes, tais detalhes que nesta pesquisa só conseguimos retomar por meio das gravações. 
Foi pensando nisso que optamos por utilizar os dois recursos: filmagem e gravação a fim de garantir a captação desses dados. Assim, conseguimos trazer para as análises das informações que serão apresentadas adiante.

Muitas discussões surgiram durante a leitura dos textos, especialmente na interpretação dos comentários do post do texto Olhos verdes, realizada no dia 01/11/2016. Os relatos a seguir retratam um diálogo com a pesquisadora sobre várias observações dos sujeitos brancos a respeito da branquitude:

Lili (branca): - A gente percebe que tem privilégios, só não faz nada.

Gran Bell (branco): As pessoas são hipócritas porque todo mundo diz que não é racista, mas fica quieto e aproveita os privilégios. É fácil não ser racista nas redes sociais. Todo mundo comenta dizendo que não é racista, que concorda com o autor do texto porque estão atrás de um computador, porque assim é fácil, mas no dia a dia é diferente. Todo mundo quer ser bonzinho na frente dos outros, não tem nenhum comentário dizendo: "eu sou racista", porque todo mundo quer parecer o que não é. Lili: - Minha irmã levou um namorado em casa e meu pai disse assim: "O que esse neguinho vai poder te dar? Então, ele é racista porque se fosse branco o namorado da minha irmã, ele não teria falado assim.

Pesquisadora: - Você já sentiu que tinha vantagens por ser branca?

Tânia (branca): - Senti, dá para perceber.

Mara (branca) - É fácil dizer no comentário do post, mas no dia a dia é difícil não ser racista. Não é racista atrás do computador. A maioria das pessoas não se incomoda com o que os outros estão passando. Porque desmascara a sociedade hipócrita.

Pesquisadora: - O que é ser hipócrita?

Mara - Falar alguma coisa que não é verdade.

Gran Bell - Todo mundo compartilhou para dizer assim: "eu sou o bonitinho da sociedade, assim, racista. Por isso comento e compartilho. Ninguém quer ser judas. (SOUTA, 2017, p. 170-171).

O aluno Gran Bell afirma que "as pessoas são hipócritas porque todo mundo diz que não é racista, mas fica quieto e aproveita os privilégios”. A consciência racial desenvolvida com as reflexões, a partir da intervenção, fez com que os sujeitos questionassem a branquitude. Os alunos criticam o que chamam de "hipocrisia", pois as pessoas não admitem que são preconceituosas. A afirmação: A GENTE PERCEBE que tem privilégios, só não faz nada (grifos meus), demonstra a constatação da própria branquitude.

Para Cardoso (2014), a braquitude tem se colocado até o presente momento como a identidade racial do branco, tendo como característica principal o privilégio racial, tendo noção 
de que o privilegiado não deixa de ser tratado da mesma forma pela sociedade. É o que as(os) alunas(os) discutem ao interpretar os comentários do post do texto Olhos Verdes.

A aluna Lili diz: "A gente percebe que tem privilégios, só não faz nada". Esse discurso revela que ela refletiu sobre a branquitude. Cardoso (2014, p. 102) observa que "tanto branco com branquitude quanto com branquidade serão tratados da mesma forma pela sociedade", então é contra a forma desigual com que brancos e negros são tratados que devemos lutar.

O autor afirma que o branco crítico antirracista, que se coloca contra o seu privilégio racial, mesmo assim não deixa de obter vantagens por ser quem é. Talvez seja a esse fato que as(os) alunas(os) estejam se referindo quando falam que é fácil concordar com o autor do texto Olhosverdes, odifícilénão ser racista. Concordamos com Cardoso (2014, p. 102) quando diz que "a construção da identidade branca antirracista é uma tarefa a ser realizada dia a dia, uma tarefa árdua enquanto o racismo persistir". Vêm à memória de Lili lembranças sobre a reação negativa do pai, quando a irmã leva um namorado negro para casa, Lili recorda e reflete: "Então, ele é racista porque se fosse branco o namorado da minha irmã, ele não teria falado assim", deslocando o olhar da vítima para o discriminador, o pai. É um movimento que questiona a branquitude.

Conforme Ribeiro (2011, p. 43), "se mostra clara a necessidade de estratégias de mediação da construção identitária dos adolescentes, de que a escola não deve se abster sob o risco de fracassar em seu objetivo de promover as transformações sociais". Com a intervenção, a menina pode parar para pensar na atitude do pai e na branquitude. Ela poderá ser diferente dele por meio dessa reflexão.

Ao analisarmos os comentários do texto Olhos Verdes, nos quais as pessoas elogiam, concordam com o autor, colocando-se contra o racismo e reconhecendo que realmente ele existe e que os privilégios dos brancos são evidentes, Gran Bell, Lili e Mara fazem uma reflexão muito importante ao afirmarem que não ser racista no discurso é fácil, mas no dia a dia é difícil não o ser. Observe-se o relato de Gran Bell: “Todo mundo comenta dizendo que não é racista. Que concorda com o autor do texto porque estão atrás de um computador, porque assim é fácil, MAS NO DIA A DIA É DIFERENTE”. (grifos meus, diário de bordo: 01/11/2016). (SOUTA, 2017, p. 172).

A reflexão acima nos reporta ao que Cardoso (2010) nos diz ao se referir à branquitude trazendo Florestan Fernandes (1978), que dizia que o brasileiro tem preconceito de ter preconceito. As(os) alunas(os) questionam se os comentários não se assemelham ao que observam na sociedade, dizer-se não racista, mas tendo atitudes racistas.

Talvez seja à consciência desse preconceito de ter preconceito a que as(os) alunas(os) estejam se referindo. Nogueira (2007) explica isso dizendo que, no Brasil, um indivíduo pode ter preconceito contra as pessoas de cor em geral, e ao mesmo tempo, ser cliente, amigo particular, admirador de determinada pessoa de cor e mesmo assim isso não implicar numa 
mudança de conceito e de atitude dele com relação às demais pessoas, assim não envolvendo uma redefinição de ponto de vista ou de atitude de sua parte.

Lopes (2016) explica que a branquitude é um lugar de vantagem sistêmica nas sociedades estruturadas na dominação racial e até mesmo o branco antirracista não se isenta desse lugar. Lopes (2016, p. 119) declara: "Refiro-me a um lugar de condições de existência material, simbólica e psíquica”. Procuramos trazer para análise os relatos que mais nos chamaram atenção, além das anotações do diário de bordo que pudessem esclarecer melhor os relatos; porém, diante da riqueza dos dados gerados durante essa pesquisa, tornou-se muito difícil fazer uma seleção dos mais importantes. Mas com certeza, como pontua Bento (2014, p. 44):

[...] ler biografias e autobiografias de pessoas brancas que têm atravessado processos semelhantes de desenvolvimento da identidade oferece aos brancos modelos para mudança. Estudar sobre brancos antirrracistas pode também oferecer aos negros a esperança de que é possível ter aliados brancos.

As(os) alunas(os) que participaram desta pesquisa são adolescentes, jovens, ou seja, encontram-se numa fase da vida em que conforme, Piza (2005) e Spósito (2009), é tida como uma fase em que se definem muitos traços das identidades sociais, mesmo sabendo que as identidades estão em constante processo de (re)construção.

Piza (2005) ressalta que a adolescência é marcada pelo aumento do foco nos conflitos psicossociais, e esses conflitos fazem parte do processo de afirmação da autonomia, face à hierarquia familiar e a valores comportamentais institucionalizados, ainda que parcialmente.

Mesmo que não tenham conseguido ainda fazer a travessia completa, a função da intervenção era fomentar essa reflexão, e muitos foram além disso, mudando de posição. As(os) alunas(os) fizeram um importante exercício de tentativa de superação da branquitude. Se dispuseram a pensar sobre as relações raciais contribuindo com raciocínios muito interessantes, ou seja, quem conseguiu refletir um pouco a partir do seu próprio espaço, conseguiu ressignificar sua branquitude a caminho de uma branquitude crítica, caminhando para uma mudança de postura, de atitude, de comportamento rumo ao que Bento (2014) nos menciona sobre a última fase em direção à identidade não racista que é a autonomia, uma nova maneira de ser branco.

Com essa nova definição, são associados sentimentos positivos que energizam os esforços pessoais para confrontar o racismo e a opressão cotidianamente. Nós, brancas(os), mesmo com nossa branquitude ressignificada, precisamos, conforme sugere Bento (2014), estar abertas(os) a novas informações e a novas formas de pensar sobre as variáveis culturais e raciais. Esse, porém, é um processo contínuo. O que almejamos expor às/aos leitoras(es) é que foi possível perceber isso pela análise dos relatos autobiográficos e pela análise do diário de bordo ao intercruzar as informações. 


\section{CONSIDERAÇÕES FINAIS}

Foi possível fazer com que as/os alunas(os) brancas(os) refletissem sobre as relações raciais e percebessem os seus papéis nas relações étnico-raciais. As contranarrativas, ou seja, as narrativas não hegemônicas trabalhadas, fizeram com que se fomentasse essa reflexão, portanto, o papel das contranarrativas foi/é importante no trabalho na perspectiva do letramento racial crítico.

Os relatos autobiográficos comprovam também o que Cardoso (2010) nos fala sobre a branquitude, que não é visível só para as pessoas negras, embora os negros sintam o seu peso em todas as suas dimensões.

Experienciamos que não é fácil educar na perspectiva do letramento racial crítico, porque há necessidade de perceber os seus privilégios, refletir, desconstruir conceitos arraigados que o tempo todo minam os discursos hegemônicos, como pudemos perceber no relato de uma aluna.

Ao observar que todas/todos conseguiram reconhecer os privilégios dos brancos e a branquitude, constatamos que um primeiro passo foi dado para uma conscientização contra a branquitude. Entretanto, a aplicação de uma intervenção talvez não seja suficiente para (re) construir identidades étnico-raciais, porque cada um possui um tempo para compreender, aprender, e isso precisou ser considerado na análise que realizamos. Foi perceptível que contribuímos com boas reflexões e ações eficientes, mas somente um trabalho, a longo prazo, poderá realmente produzir melhores resultados. Acreditamos que a ressignificação da branquitude vem primeiramente no sentido de reconhecê-la, para posteriormente o branco negar a sua supremacia, conforme Edith Piza (2005). A conscientização do branco poderá transformar a sociedade em menos excludente com ações que venham de encontro à branquidade.

A intervenção teve a função de provocar uma reflexão sobre as questões raciais, alguns fizeram um movimento que demonstra ser o primeiro passo em direção à ressignificação da branquitude, outros foram além, demonstrando mudança de posicionamento.

É de se esperar, pelo que acabamos de elencar, que nem todos esses adolescentes/ jovens tenham realizado um movimento em direção à ressignificação da branquitude, por isso o resultado obtido com esta intervenção foi melhor do que o esperado, pois fomentou a reflexão sobre o papel do branco nas relações raciais. Este trabalho, que teve uma intervenção na perspectiva do letramento racial crítico e na perspectiva da educação antirracista, não teve a pretensão de conseguir mudar de uma hora para outra a maneira de pensar das(os) alunas(os), mas sim provocar uma reflexão sobre o papel do branco nas relações raciais.

Quando conseguimos fazer as(os) estudantes pensarem sobre o assunto, reverem conceitos, estamos abrindo um caminho para um mundo melhor que seja menos preconceituoso. Bento (2014) explica que os estudos brasileiros ultimamente não têm focado na interferência 
da branquitude como uma guardiã silenciosa de privilégios e têm silenciado sobre a herança branca da escravidão.

Segundo Ferreira (2014, p. 250), "vale dizer que, para termos uma sociedade mais justa e igualitária, temos que mobilizar todas as identidades de raça branca e negra para refletir sobre raça e racismo e fazer um trabalho crítico no contexto escolar [...]". O conjunto de instrumentos pedagógicos de que o professor lança mão para trabalhar nessa perspectiva é o letramento racial crítico.

Nossa sugestão é a de que trabalhos como os de Ferreira (2014) continuem sendo realizados na formação de professores, que o letramento racial crítico seja trabalhado primeiramente com os professores e com as equipes multidisciplinares das escolas, também sigam em uma formação nessa perspectiva. Cremos que as contranarrativas apresentadas nessa intervenção desempenharam um papel primordial para fomentar reflexões a respeito das questões raciais, focando também no papel do branco para a manutenção do racismo e proporcionando uma abertura para a ressignificação da branquitude.

Para finalizar, recordamos Ferreira (2015) ao ressaltar a importância da preparação de nós professores para utilização do letramento racial crítico. A autora comenta que se os professores estiverem preparados para utilizar o letramento racial crítico, eles podem colaborar para a formação de identidades raciais branca e negra. Para que todos tenham orgulho do seu pertencimento racial, é preciso que entendamos como o racismo está estruturado na sociedade. Este trabalho tentou mostrar isso às (aos) alunas(os), para que se mude a forma de agir no sentido de formar cidadãos que as possam construir uma sociedade mais justa.

Também ressaltamos as palavras de Gomes (2005) ao afirmar, que se queremos lutar contra o racismo, precisamos reeducar as nossas famílias, as(os) profissionais da educação, a sociedade e a escola. A autora complementa argumentando que pesquisas, estudos precisam ser realizados, e para isso é preciso compreender mais sobre a história da África e da cultura afro-brasileira. É preciso ter orgulho da significante, respeitável e marcante história dos ancestrais africanos no Brasil.

Por esta razão esta pesquisa também revela-se muito importante, pois vem de um contexto educacional que possui uma equipe multidisciplinar que trabalha questões raciais. Este trabalho vem para agregar ao que está sendo realizado na escola onde a pesquisa foi promovida, salientando a importância de se educar para as relações raciais e trazer o branco para o centro das discussões.

\section{REFERÊNCIAS}

BENTO, M. A. S. Branqueamento e Branquitude no Brasil. In: BENTO, M. A. S. (Org.); CARONE, I. (Org.). Psicologia Social do Racismo: Estudos sobre branquitude e branqueamento no Brasil. 6. ed., Petrópolis, RJ: Vozes, 2014, p. 25-57. 
BESSET, V. L.; CASTRO, L. R. de. Pesquisa-intervenção na infância e juventude: construindo caminhos. Tararepa, RJ: FAPERJ: NAU, 2008. Disponível em: <http://www.scielo.br/scielo. php?script=sci_arttext\&pid=S1414-98932008000200005>. Acessado em: 10 jun. 2016.

BRASIL. Lei 10.639 de 9 de janeiro de 2003. Altera a Lei no 9.394, de 20 de dezembro de 1996, que estabelece as diretrizes e bases da educação nacional, para incluir no currículo oficial da Rede de Ensino a obrigatoriedade da temática «História e Cultura Afro-Brasileira», e dá outras providências. Diário Oficial da União. Brasília, 9 jan. 2003. Disponível em: $<$ http://www. planalto.gov.br/ccivil_03/leis/2003/lio.639.htm>. Acessado em: 21 jan. 2017.

CARDOSO, L. $\mathrm{O}$ branco ante a rebeldia do desejo: um estudo sobre a branquitude no Brasil. 2014, 290f. Tese (Doutorado em Ciências Sociais) - Universidade Estadual Paulista, Araraquara, SP, 2014.

CARDOSO, L. O branco-objeto: o movimento negro situando a branquitude. Rev. de Estudo e Pesquisa em Educação de Juiz de fora. Juiz de Fora, MG, v. 13, n. 1, jan./jun., 2011. Disponível em: $<\mathrm{http}$ ///www.observatoriodonegro.org.br/pdf/o-branco-objeto-o-movimento-negro situandoa-branquitude-por-lourenco-cardoso.pdf.>. Acessado em: 17 out. 2016.

CAVALLEIRO, E. Do silêncio do lar ao silêncio escolar: racismo, preconceito e discriminação na educação infantil. São Paulo: Contexto, 2012.112 p.

CORTI, A. P.; SOUZA, R. Diálogos com o mundo juvenil-subsídios para educadores. São Paulo: Ação Educativa, 2005. 112 p.

DOLZ, J.; SCHNEUWLY, B. Gêneros Orais e Escritos na Escola. Tradução de Roxane Rojo e Glaís Sales Cordeiro. Campinas, SP: Mercado de Letras, 2004.320 p.

FERREIRA, A. de J. Formação de Professores Raça/Etnia reflexões e sugestões de materiais de ensino em português e inglês. 2. ed., Cascavel, PR: Assoeste. 2006. 148 p.

FERREIRA, A. de J. Narrativas Autobiográficas de Professores de Línguas na Universidade: Letramento Racial Crítico e Teoria Racial Crítica. In: FERREIRA, A. de J. (Org.) Narrativas Autobiográficas de Identidades Sociais de Raça, Gênero, Sexualidade e Classe em Estudos da Linguagem. Campinas, SP: Pontes, 2015, p.97-143.

FERREIRA, A. de J. Narrativas e Contranarrativas de Identidade Racial de Professores de Línguas. Revista da ABPN. Florianópolis, SC: ABPN. v.6, n.14, p. 236-263, jul./out., 2014.

GOMES, N. L. Alguns termos e conceitos presentes no debate sobre relações raciais no Brasil: uma breve discussão. In: BRASIL, Ministério da Educação e Cultura. Educação antirracista: caminhos abertos pela Lei Federal $n^{\circ}$ 10.639/03. Col. Educação para todos. Brasília: Ministério da Educação. Secretaria de Educação Continuada. Alfabetização e Diversidade, 2005. p. 39-63.

JESUS, C. M. de. 0 privilégio da brancura na escola pública: uma etnografia no colégio estadual Edvaldo Brandão Correia em Cachoeira - BA. 2014, 121f. Dissertação (Mestrado em Ciências Sociais) - Universidade Federal do Recôncavo Baiano, Cachoeira, BA, 2014. 
LABORNE, A. A. de P. Branquitude em foco: análises sobre a construção da identidade branca de intelectuais no Brasil. Belo Horizonte. 2014, 159f. Tese (Doutorado em Educação Conhecimento e Inclusão Social) - Universidade Federal de Minas Gerais, Belo Horizonte, 2014.

LOPES, J. S. Lugar de branca/o ea/o "branca/o fora delugar: Representações sobre branquitude, e suas possibilidades de antirracismo entre negra/os branca/os do/ no Movimento Negro em Salvador-BA. 2016, 255f. Dissertação (Mestrado em Antropologia Social e Cultural) Universidade Federal de Pelotas, Pelotas, RS, 2016.

MARCUSCHI, L. A. Gêneros textuais no ensino de língua. In: MARCUSCHI, L. A. Produção Textual: Análise de gêneros e compreensão. São Paulo: Parábola, 2008. cap.2. p. 145-226.

MOREIRA, C. Branquitude é branquidade? Uma revisão teórica da aplicação dos termos no cenário brasileiro. Revista da ABPN. Florianópolis, v. 6, n. 13, p. 73-87, mar./jun. 2014.

NOGUEIRA, O. Preconceito racial de marca e preconceito racial de origem: sugestão de um quadro de referência para a interpretação do material sobre relações raciais no Brasil. Revista Tempo social, São Paulo, v. 19, n. 1, p. 287-308, 2007.

NOGUEIRA, S. G. Políticas de Identidade, Branquitude e Pertencimento Étnico-Racial. In: BENTO, M. A. da S. (Org.); SILVEIRA, M. de J. (Org.); NOGUEIRA, S. G. Identidade, branquitude e negritude construções para a psicologia social no Brasil: novos ensaios relatos e experiências e de pesquisa. São Paulo. ed. Casa do Psicólogo, 2014. p. 49-63.

ORLANDO, A. F. Gênero e diversidade na escola: Multiletramentos em aulas de língua portuguesa. 2013, 194f. Dissertação (Mestrado em Letras) - Universidade Estadual do Oeste do Paraná, Cascavel, PR, 2013.

RIBEIRO, C. R. A. Sujeitos à escola ou sujeitos da escola?: A elaboração das identidades de alunos do Ensino Médio durante a produção de um roteiro de vídeo. 2011, 113f. Dissertação (Mestrado em Educação) - Pontifícia Universidade Católica do Rio de Janeiro, Rio de Janeiro, 2011.

ROJO, R. Letramentos Múltiplos, escola e inclusão social. São Paulo: Parábola, 2009. 128 p.

SOUTA, M. Quando me dei conta de que era negra(o)/branca(o)?: Um estudo a partir de relatos autobiográficos de estudantes adolescentes. 2017, 234f. Dissertação (Mestrado em Estudos da Linguagem) - Universidade Estadual de Ponta Grossa, Ponta Grossa-PR, 2017.

SOUZA, A. L. S.; CORTI, A. P.; MENDONÇA, M. Letramentos no Ensino Médio. São Paulo: Parábola Editorial, 2012. 122 p.

SPÓSITO, M. P. O Estado da Arte sobre a juventude: uma introdução. In: SPÓSITO, M. P. 0 Estado da Arte sobre juventude na pós-graduação brasileira: Educação, Ciências Sociais e Serviço Social (1999-2006). v. 1. Belo Horizonte, MG: Argivmentvm, 2009. p. 11- 16. (Coleção Advcere). 
PIZA, E. Adolescência e racismo: uma breve reflexão. In: I Simpósio Internacional do Adolescente n 1., 2005, São Paulo, SP. Anais do I Simpósio Internacional do Adolescente. São Paulo, SP: Universidade de São Paulo-USP, 2005. Disponível em: <Http://www.proceedings. scielo.br/scielo.php?pid=MSC0000000082005000100022\&script=sci_arttext $>$. Acessado em: 07 jun. 2016.

Recebido para publicação em 31 de Dezembro de 2019. Aceito para publicação em 22 de Janeiro de 2020. 